\title{
Mechanisms in anti-inflammation and resolution: the role of lipoxins and aspirin-triggered lipoxins
}

\section{I.M. Fierro and} C.N. Serhan
Center for Experimental Therapeutics and Reperfusion Injury, Department of Anesthesiology, Perioperative and Pain M edicine, Brigham and W omen's Hospital, Harvard Medical School, Boston, MA, USA

\section{Correspondence \\ C.N. Serhan \\ Center for Experimental Therapeutics and Reperfusion Injury \\ Thorn Building for Medical Research \\ Brigham and Women's Hospital \\ 75 Francis Street, 7th Floor \\ Boston, MA 02115 \\ USA \\ Fax: + 1-617-278-6957 \\ E-mail: \\ cnserhan@ zeus.bwh.harvard.edu}

Research supported in part by the National Institutes of $\mathrm{H}$ ealth (Nos. R01-GM 38765, P01-DK50305 and P01-DE13499). I.M. Fierro was the recipient of a CAPES fellowship.

The present address of I.M. Fierro is Departamento de Farmacologia e Psicobiologia, Instituto de Biologia Roberto Alcântara Gomes, UERJ, Av. 28 de Setembro, 87, fundos, 5 andar, 20551-030 Rio de Janeiro, RJ, Brasil. E-mail: iolanda@uerj.br

Received N ovember 29, 2000 Accepted February 12, 2001

\begin{abstract}
Multicellular host responses to infection, injury or inflammatory stimuli lead to the formation of a broad range of chemical mediators by the host. The integrated response of the host is essential to health and disease; thus it is important to achieve a more complete understanding of the molecular and cellular events governing the formation and actions of endogenous mediators of resolution that appear to control the duration of inflammation. Lipoxins are trihydroxytetraene-containing lipid mediators that can be formed during cell-cell interactions and are predominantly counterregulators of some well-known mediators of inflammation. Since this circuit of lipoxin formation and action appears to be of physiological relevance for the resolution of inflammation, therapeutic modalities targeted at this system are likely to have fewer unwanted side effects than other candidates and current antiinflammatory therapies. Here, we present an overview of the recent knowledge about the biosynthesis and bioactions of these anti-inflammatory lipid mediators.
\end{abstract}

\section{Introduction}

The vascular and cellular responses of both acute and chronic inflammation are mediated by endogenous chemical factors derived from plasma or cells and triggered by the inflammatory stimulus (1). These different factors play key roles, not only initiating but also regulating the host responses, like the recently discovered inosine monophosphate-AMP deaminase system (2). Such mediators, acting alone, in combination, or in tandem, then amplify the inflammatory response and influence its evolution and the outcome of the process (Figure 1).

Biosynthesis of mediators by transcellular and cell-cell interactions is recognized as an important means of amplifying and generating lipid-derived mediators, particularly those produced by lipoxygenases (LO). Arachidonic acid and its oxygenation products may transfer from one cell to another during cellcell interaction undergoing further transformation to biologically active "pro-" and "antiinflammatory" compounds. Results from numerous studies have shown that lipoxins are formed in vitro from endogenous sources of arachidonate in isolated cells and also in vivo and across many species, from fish to humans. This review addresses the major routes and biological actions of lipoxins and whether their formation and actions can be of therapeutic value in regulating inflammation and other pathophysiologic events of 
interest in human disease.

\section{Biosynthesis}

Multicellular host responses to infection, injury or inflammation stimuli lead to the formation of lipoxins ("lipoxygenase interaction products"), trihydroxytetraene-containing bioactive lipid mediators that carry potent anti-inflammatory signals. First re-

Figure 1. Inflammation: endogenous chemical mediators. Inflammatory responses are mediated by a range of endogenous mediators/signals as the wellestablished classes of lipid mediators, proteins and reactive oxygen species (ROS) and more recently also including gases and nucleotides. NO, nitric oxide; $\mathrm{CO}$, carbon monoxide; IMP, inosine monophosphate; PAF, platelet-activating factor; LPA, lysophosphatidic acid.

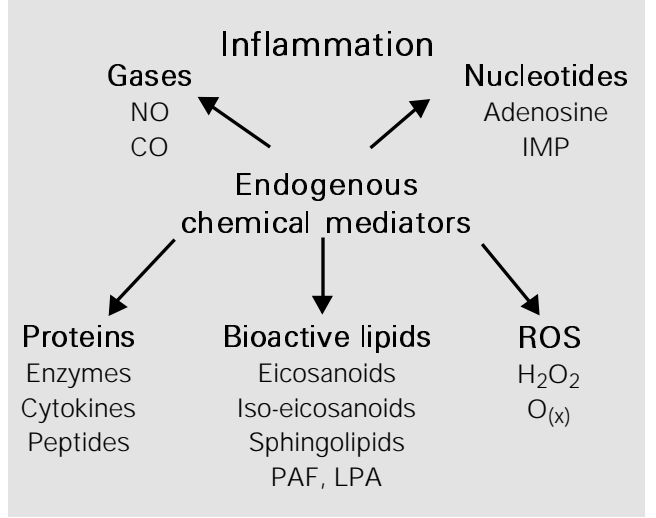

ported in 1984 in mixed suspensions of human leukocytes incubated with exogenous substrates (3), lipoxins are now known to be generated in humans during cell-cell interactions by one of at least three biosynthetic routes working independently or in concert, in particular biological settings or tissues.

During lipoxin formation, molecular oxygen is inserted at two sites in arachidonic acid (C20:4) by distinct LO that are often segregated into different cell types. The first report on lipoxin biosynthesis rationalized lipoxin generation by routes involving insertion of molecular oxygen into carbon 15 of C20:4, predominantly in the $S$ configuration, which implied the involvement of a 15-LO (3). Eicosanoid products of 15-LO in airway epithelial cells or monocytes, $15 S$-hydroperoxyeicosatetraenoic acid (15S-H(p)ETE), or the reduced alcohol form 15S-hydroxyeicosatetraenoic acid (15S-HETE) can serve as substrates for neutrophil (PMN) 5-LO and lead to the formation of the trihydroxy-
Figure 2. Lipoxin (LX) and aspirin-triggered 15-epi-lipoxin biosynthesis. Illustration of the three main transcellular routes to generate lipoxins and 15-epi-lipoxins in mammalian tissues. Each of these is an independent route initiated by site selective addition of molecular oxygen to arachidonic acid in the donor cell type of origin. LO, lipoxygenase; $L T$, leukotriene; PMN, neutrophils; 15S-H(p)ETE, 15S-hydroxyperoxyeicosatetraenoic acid; 15R-HETE, 15R-hydroxyeicosatetraenoic acid; COX-2, cyclooxygenase; IL-1ß, interleukin $1 \beta_{\text {; }}$ TNF- $\alpha$, tumor necrosis factor $\alpha$.
Transcellular lipoxin biosynthesis

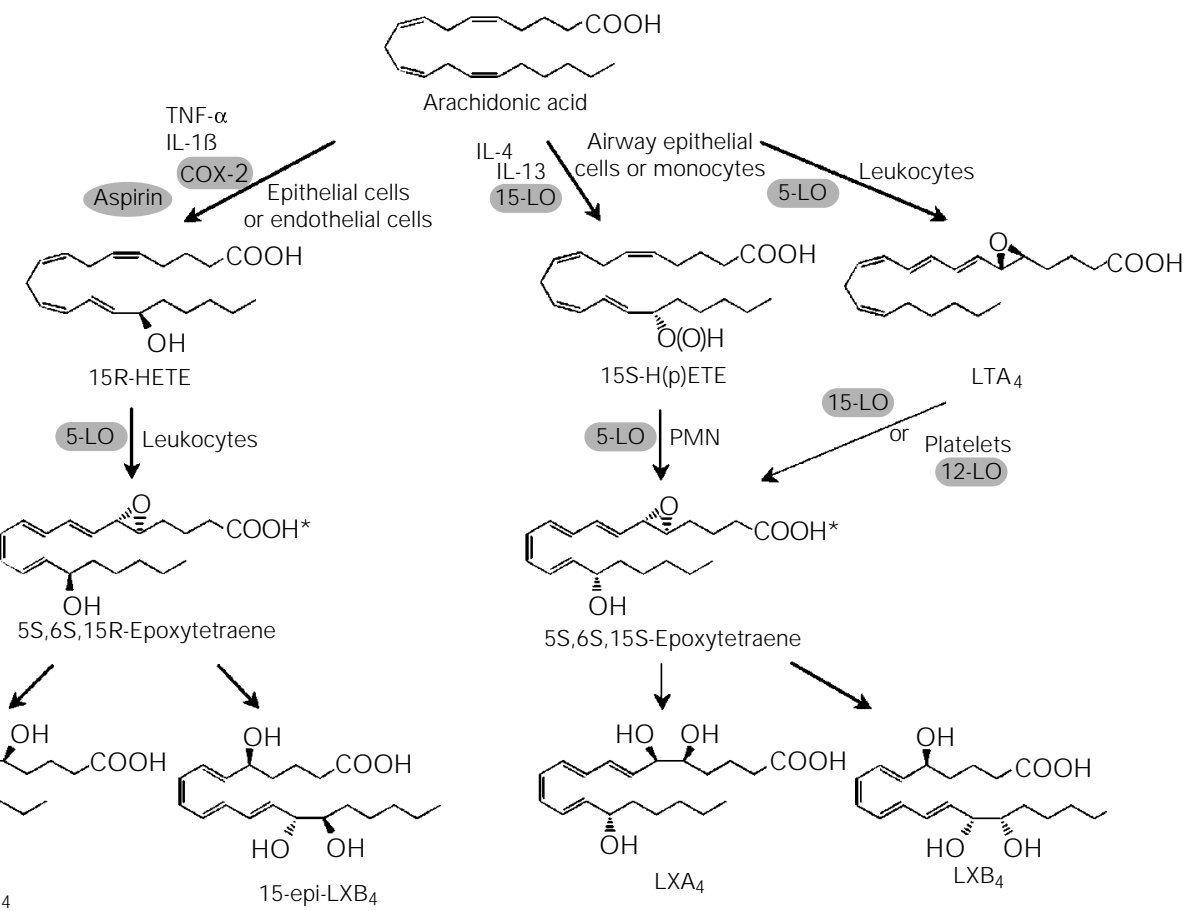

Lipoxins 
tetraenes, lipoxin $\mathrm{A}_{4}\left(\mathrm{LXA}_{4}\right)$ and lipoxin $\mathrm{B}_{4}$ $\left(\mathrm{LXB}_{4}\right)$ (Figure 2). These lipoxins retain their precursors' alcohol configuration to carry their carbon 15 alcohol in the $S$ configuration.

The second pathway for lipoxin biosynthesis was determined for interactions that occur predominantly within the vasculature between 5-LO, present in myeloid cells, and 12-LO, present in platelets (3). The 5-LO product leukotriene $\mathrm{A}_{4}\left(\mathrm{LTA}_{4}\right)$ is rapidly taken up by the platelets and converted via a 12-LO-dependent mechanism to lipoxins (Figure 2). Since more than $50 \%$ is released from the cell of origin (3), $\mathrm{LTA}_{4}$ serves as an intermediate for both intracellular and transcellular eicosanoid biosynthesis. During neutrophil-platelet interaction and co-activation, $\mathrm{LTA}_{4}$ has multiple potential enzymatic and non-enzymatic fates, including a) conversion by 12 -LO to $\mathrm{LXA}_{4}$ and $\mathrm{B}_{4}, \mathrm{~b}$ ) nonenzymatic hydrolysis (which occurs in seconds in aqueous environments), c) conversion by $\mathrm{LTA}_{4}$ hydrolase to $\mathrm{LTB}_{4}$ (a potent neutrophil and eosinophil chemoattractant) or d) converted by $\mathrm{LTC}_{4}$ synthase to $\mathrm{LTC}_{4}$ (slow reacting substance of anaphylaxis). Because $\mathrm{LTB}_{4}$ and $\mathrm{C}_{4}$ carry potent proinflammatory actions and lipoxins inhibit leukotriene-mediated responses in vivo, the balance of leukotriene to lipoxin formation is critical to cellular responses.

\section{Aspirin-triggered 15-epi-lipoxin pathway}

Recently, a third major pathway for lipoxin generation was discovered that involves aspirin and the actions of cyclooxygenase (COX) 2 and 5-LO (4). Endothelial and epithelial cells express COX-2 in response to diverse stimuli such as cytokines, hypoxia and bacterial infections. Aspirin acetylates COX-2 and switches its catalytic activity for conversion of $\mathrm{C} 20: 4$ to $15 R$ HETE in lieu of prostanoid biosynthesis. $15 R$-HETE is released from endothelial and epithelial cells and transformed by leuko- cyte 5-LO, via transcellular routes, to 15 epimer lipoxins (or aspirin-triggered lipoxins, ATL) (Figure 3).

The route of lipoxin formation depends on the cells and enzymes present therein and can be subject to modulation by cytokines (reviewed in 5). For example, interleukin 4 (IL-4) and IL-13, which are thought to be negative regulators of the inflammatory response, both increase 15-LO expression and activity, thereby enhancing lipoxin formation. Proinflammatory cytokines up-regulate 5-LO (e.g., granulocyte/macrophage colony stimulating factor (GM-CSF) and IL-3) and COX-2 (e.g., IL-1ß and tumor necrosis factor (TNF)- $\alpha$ ) activities (reviewed in 5) which

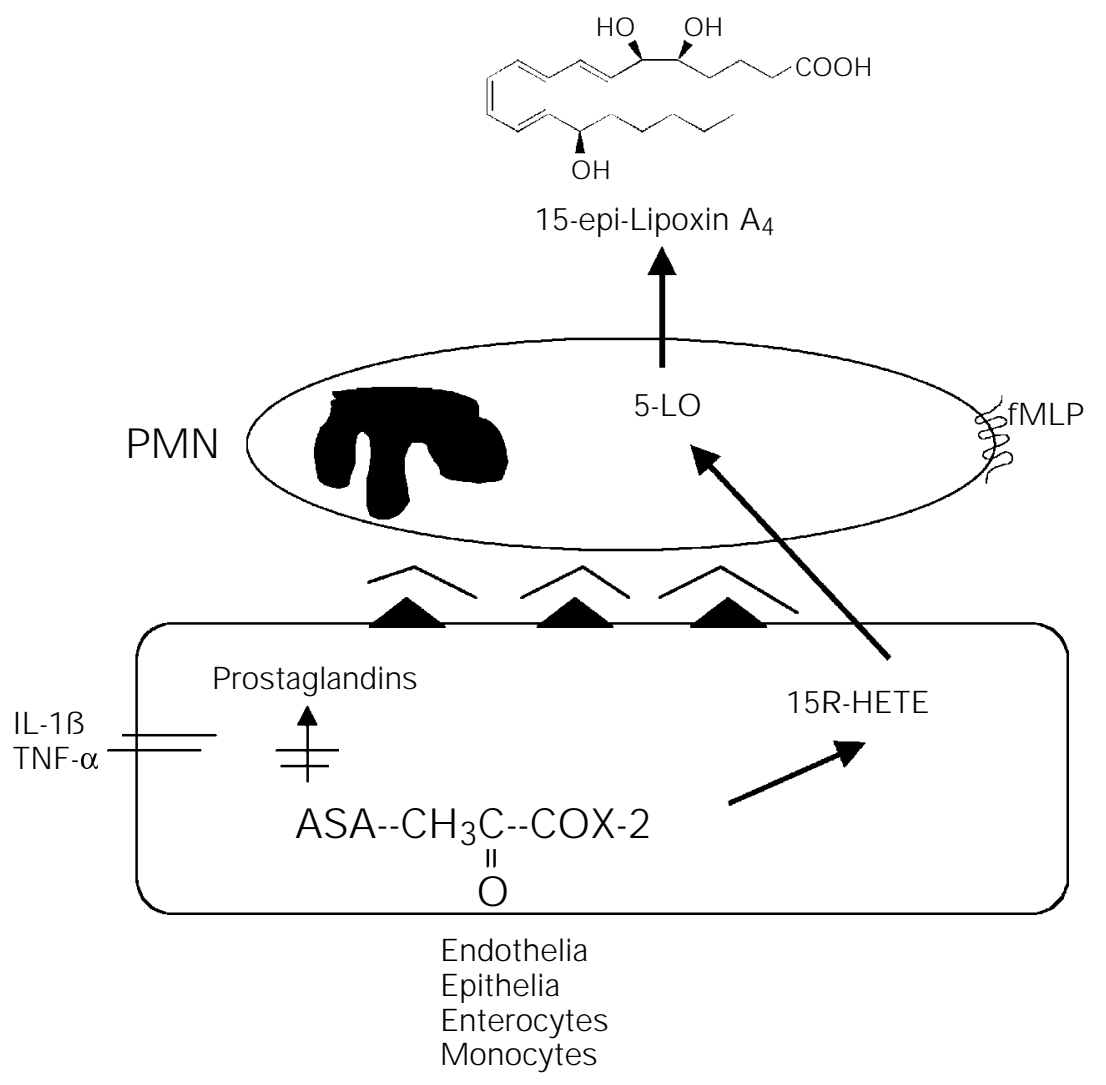

Figure 3. Aspirin (ASA)-triggered 15-epi-lipoxin pathway. Cytokine exposure induces COX-2 expression in vascular endothelial cells. This isozyme is acetylated by ASA, and cell activation via membrane receptors generates $15 R$-hydroxyeicosatetraenoic acid (15R-HETE) that is transformed by the 5-lipoxygenase (5-LO) of adhering neutrophils (PMN) to 15-epilipoxins. fMLP, formyl-methionyl-leucyl-phenylalanine; IL-1ß, interleukin $1 ß$; TNF- $\alpha$, tumor necrosis factor $\alpha$. 
are crucial to the formation of both lipoxins and ATL. Furthermore, addition of exogenous C20:4 to GM-CSF-primed neutrophils co-incubated with platelets enhances receptor-triggered formation of $\mathrm{LXA}_{4}$ with either formyl-methionyl-leucyl-phenylalanine (fMLP) or platelet-derived growth factor (6), establishing that lipoxins are indeed generated from endogenous sources of arachidonic acid following receptor-ligand interactions.

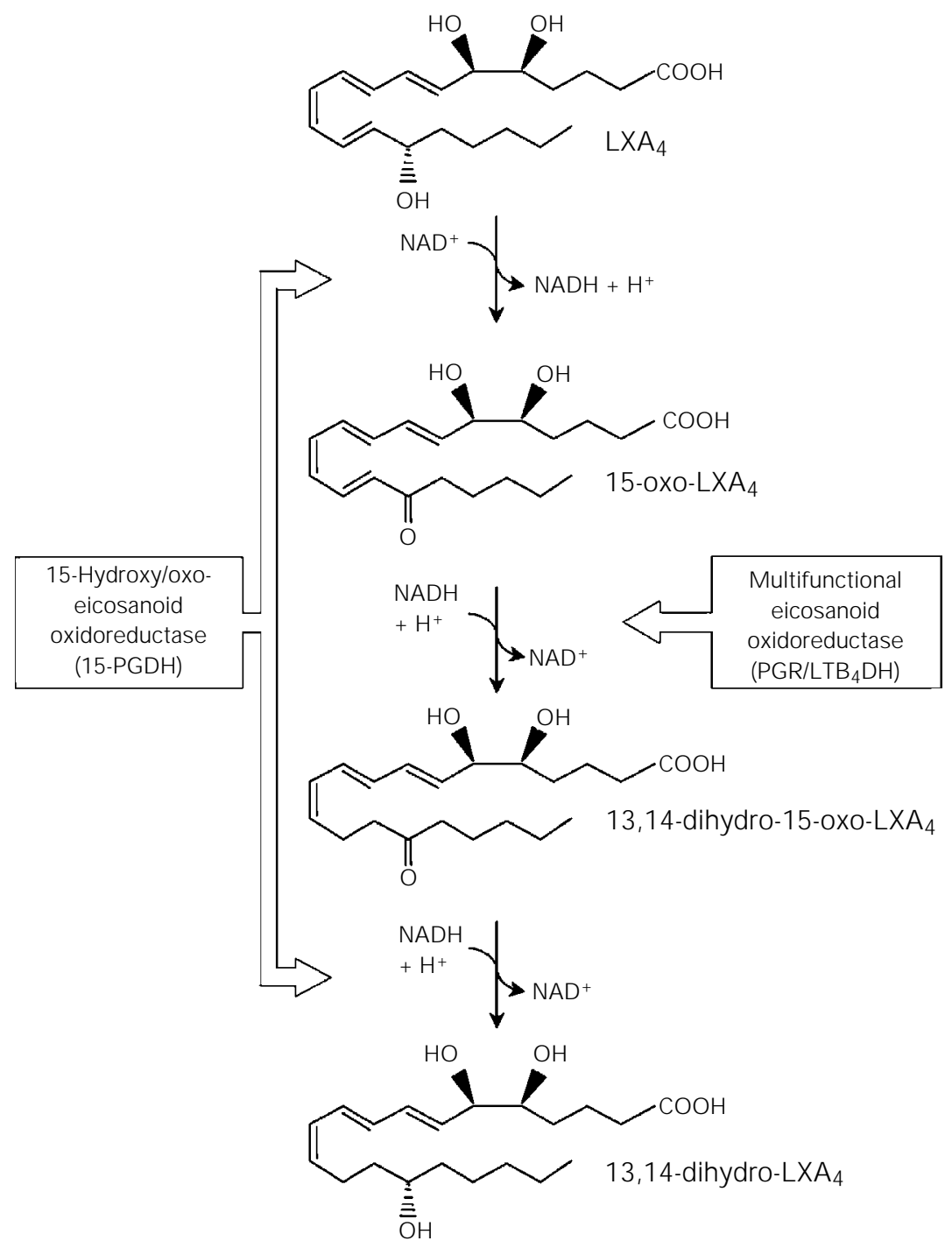

Figure 4. Lipoxin (LX) metabolic inactivation. The initial step in $\mathrm{LXA}_{4}$ inactivation is dehydrogenation of the 15-hydroxyl group, catalyzed by $15-\mathrm{PGDH}$ to yield $15-0 \mathrm{-xo}-\mathrm{LXA}_{4}$. PGR/ $\mathrm{LTB}_{4} \mathrm{DH}$ catalyzes the reduction of the 13,14 double bond of 15 -oxo- $\mathrm{LXA}_{4}$ to give 13,14 dihydro-15-oxo-LXA 4 . This product serves as a substrate for 15-PGDH, which catalyzes the reduction of the C15-oxo group to give 13,14-dihydro-LXA 4 .
Although first described in human leukocytes (3), lipoxins are generated by bovine, porcine and rat cells, including basophils and macrophages (reviewed in 7). It appears that both the basic structure of lipoxins and the means of generating these compounds are conserved in the course of evolution. In this regard, it was shown that leukocytes or isolated phagocytic cells from several species of fish (trout, salmon, catfish) could generate substantial amounts of lipoxin from endogenous sources of substrate (8).

By taking advantage of $\mathrm{LXA}_{4}$ 's unique overall three-dimensional conformation, an ELISA was developed for rapid detection of LXA $_{4}$ in biologically derived samples. This assay has proven to be sensitive and selective, showing no cross-reactivity for $5 S$ HETE, $12 S$-HETE, 15S-HETE, $\mathrm{LTB}_{4}, \mathrm{LTC}_{4}$, $\mathrm{LTD}_{4}$ or arachidonic acid, and has an $\mathrm{LXA}_{4}$ detection limit of $90 \mathrm{fmol} / \mathrm{ml}$. Furthermore, a selective ELISA for the aspirin-triggered 15-epi-LXA 4 was also recently developed which shows little cross-reactivity with native $\mathrm{LXA}_{4}$ or other eicosanoids (9). Thus, the availability of appropriate quantitative methods for lipoxins, including LC/MS/MS (9), as is the case for other eicosanoids, is a critical component in assessing the association between lipoxin formation and their potential involvement in both physiological and pathophysiological events.

\section{Mechanisms of inactivation}

Lipoxins, as other autacoids, are rapidly biosynthesized in response to stimuli, act locally and then are rapidly enzymatically inactivated. The major route of lipoxin inactivation is through dehydrogenation by monocytes that convert $\mathrm{LXA}_{4}$ to 15 -oxo- $\mathrm{LXA}_{4}$, followed by specific reduction of the double bond adjacent to the ketone (10) (Figure 4). 15-Hydroxy/oxo-eicosanoid oxidoreductase (15-PGDH) catalyzes the oxidation of $\mathrm{LXA}_{4}$ to 15 -oxo- $\mathrm{LXA}_{4}$. This compound is biologically inactive and is further converted to 
13,14-dihydro-15-oxo- $\mathrm{LXA}_{4}$ by the action of $\mathrm{LXA}_{4} / \mathrm{PGE}$ 13,14-reductase/ $/ \mathrm{LTB}_{4}$ hydroxydehydrogenase $\left(\mathrm{PGR} / \mathrm{LTB}_{4} \mathrm{DH}\right)$. Moreover, reduction of the 15-oxo group by 15-PGDH yields 13,14-dihydro-LXA 4 , revealing an additional catalytic activity for this enzyme (11). $\mathrm{LXB}_{4}$ can also be dehydrogenated by 15-PGDH at carbon 5 to produce 5-oxo- $\mathrm{LXB}_{4}$, therefore sharing a common route of inactivation (12). It has recently been shown that 15 -oxo- $\mathrm{LXA}_{4}$ is also produced from $\mathrm{LXA}_{4}$ in mouse whole blood (13), suggesting that the mouse shares with humans a common pathway for $\mathrm{LXA}_{4}$ inactivation.

\section{Lipoxin and ATL stable analogs}

In view of the rapid transformation and inactivation of lipoxin by monocytes and, potentially, other cells in vivo, it was highly desirable to design lipoxin analogs that would resist this metabolism and maintain their structural integrity and potential beneficial biological actions. Lipoxin analogs were constructed with specific modifications of the native structures of $\mathrm{LXA}_{4}$ and $\mathrm{LXB}_{4}$, such as the addition of methyl groups to carbon 15 and carbon 5 of the $\mathrm{LXA}_{4}$ and $\mathrm{LXB}_{4}$ structures, respectively, to block dehydrogenation by 15 -PGDH. $15 R / S$-methyl-LXA ${ }_{4}$ is a racemic stable analog of both $\mathrm{LXA}_{4}$ and 15epi-LXA 4 . Additional analogs of $\mathrm{LXA}_{4}$ were synthesized with a phenoxy group attached to carbon 16 and replacing the $\omega$-end of the molecule. This design permits 16-phenoxy$\mathrm{LXA}_{4}$ to resist potential $\omega$-oxidation and to be protected from dehydrogenation in vivo. Fluoride was added to the para-position of the phenoxy ring to yield 16-(para-fluoro)phenoxy-LXA $\mathrm{L}_{4}$ in order to hinder degradation of the phenoxy ring. The aspirin-triggered counterpart of 16-(para-fluoro)-phenoxy-LXA 4 , 15-epi-16-(para-fluoro)-phenoxy-LXA 4 , was also synthesized. These modifications not only prolong the half-life of the compounds in blood but also enhance their bioavailability and bioactivity (13).

The ATL are less effectively converted in vitro to their 15-oxo metabolite than $\mathrm{LXA}_{4}$ (10). This indicates that the dehydrogenation step is highly stereospecific and suggests that, when ATL are generated in vivo, their biological half-life is increased by about two-fold compared to that of native $\mathrm{LXA}_{4}$, thereby enhancing their ability to evoke bioactions. Hence, biologically stable analogs of lipoxin and ATL can be engineered to enhance their bioactions, a fact suggesting that they are useful tools for the development of novel therapeutic modalities.

\section{Bioactions}

\section{Vasoactive actions}

Lipoxins display vasodilatory and counterregulatory roles in in vivo and in vitro models $(7,14)$. $\mathrm{LXA}_{4}$ and $\mathrm{LXB}_{4}$ promote vasorelaxation and relax the aorta and pulmonary arteries (Table 1). $\mathrm{LXA}_{4}$ reverses the precontraction of the pulmonary artery induced by prostaglandin $F_{2 \alpha}$ and endothelin-1. The mechanisms of $\mathrm{LXA}_{4}$ - and $\mathrm{LXB}_{4}$ induced vasodilatation involve endotheliumdependent vasorelaxation and involve prostaglandin-dependent and -independent pathways (reviewed in 14). In certain tissues, lipoxin can stimulate the formation of, for example, prostacyclin by endothelial cells (29), which can contribute to vasodilatation. These prostanoid-dependent actions of lipoxin are inhibited by COX inhibitors (14) and indicate that lipoxins can stimulate the biosynthesis of a second set of mediators. These also include lipoxin-stimulated generation of nitric oxide (33), which may mediate a component of lipoxin-regulated vascular tone.

\section{Immunomodulatory actions}

The actions of lipoxins contrast with those of most other lipid mediators that are prima- 
rily proinflammatory, such as leukotrienes, platelet-activating factor (PAF) and prostanoids. It is now appreciated that lipoxins, $\mathrm{LXA}_{4}$ in particular, are potent counterregulatory signals in vitro and in vivo for endogenous proinflammatory mediators, including lipids (leukotrienes, PAF) and cytokines (TNF- $\alpha$, IL-6), resulting in inhibition of leukocyte-dependent inflammation (reviewed in 34). Lipoxins display selective actions on leukocytes (Table 1) that include a) inhibition of neutrophil chemotaxis (15), b) transmigration through epithelial cells (16), and c) adhesion and transmigration with endothelial cells (17). $\mathrm{LXA}_{4}$ and ATL inhibit $\mathrm{PMN}$-initiated second-organ injury in an ischemia-reperfusion model using $\mathrm{LTB}_{4}$ receptor transgenic mice (35), suggesting an endogenous compensatory or protective role to limit PMN trafficking and PMN-mediated damage.

$\mathrm{LXB}_{4}$ has not been studied as extensively as $\mathrm{LXA}_{4}$; it is chemically and biologically less stable because it isomerizes rapidly in vitro. Therefore, it has been more difficult to handle previously, but now stable $\mathrm{LXB}_{4}$ analogs have been prepared (12) that will help to expand the evaluation of their biological roles. There are specific and potent actions attributed to $\mathrm{LXB}_{4}$, including stimulating proliferation and differentiation of granulocyte-monocyte colonies from human mononuclear cells and sleep induction. In addition to its specific actions, $\mathrm{LXB}_{4}$ also shares actions with $\mathrm{LXA}_{4}$, selectively stimulating human peripheral blood monocytes and inhibiting human neutrophil transmigration and adherence as well as PMN-mediated increases in vascular permeability in mice $(3,34)$.

A considerable amount of data has well documented that lipoxin actions are closely linked with cytokine networks. In human enterocytes, $\mathrm{LXA}_{4}$ and $\mathrm{LXA}_{4}$ analogs inhibit IL8 release at the gene transcriptional level (26). This report is consistent with recent findings

Table 1. Biological actions of lipoxins.

\begin{tabular}{|c|c|c|}
\hline Cell type/tissue & Action & Reference \\
\hline \multirow[t]{5}{*}{ Neutrophils } & - Inhibit chemotaxis, adherence and transmigration & 10,15 \\
\hline & - Inhibit PMN-epithelial and endothelial cell interactions & 16,17 \\
\hline & - Block superoxide anion generation & 18 \\
\hline & - Inhibit CD11b/CD18 expression and IP 3 formation & 19,20 \\
\hline & - Modulate L-selectin expression & 21 \\
\hline Monocytes & $\begin{array}{l}\text { - Stimulate chemotaxis and adhesion to laminin without } \\
\text { increasing cytotoxicity }\end{array}$ & 22 \\
\hline Eosinophils & - Inhibit migration/chemotaxis & 23 \\
\hline Natural killer cells & - Block cytotoxicity & 24 \\
\hline Myeloid progenitors & - Stimulate myeloid bone marrow-derived progenitors & 25 \\
\hline \multirow[t]{2}{*}{ Enterocytes } & - Inhibit TNF- $\alpha$-induced IL-8 expression and release & 26 \\
\hline & - Inhibit Salmonella typhimurium-induced IL-8 & 27 \\
\hline Fibroblasts & - Inhibit IL-1ß-induced IL-6, IL-8 and M M P-3 production & 28 \\
\hline \multirow[t]{2}{*}{ Endothelia (HUVEC) } & - Stimulate protein kinase C-dependent prostacyclin formation & 29 \\
\hline & - Block P-selectin expression & 30 \\
\hline Mesangial cells & - Inhibit LTD4-induced proliferation & 31 \\
\hline Pulmonary artery & $\begin{array}{l}\text { - Induces relaxation and reverses precontraction by } \\
\mathrm{PGF}_{2} \text { or endothelin-1 }\end{array}$ & 14 \\
\hline Bronchi & - Relaxation after precontraction by peptido-leukotrienes & 32 \\
\hline
\end{tabular}


showing that synthetic lipoxin analogs abolish the allergen-induced eotaxin formation (23) and suppress TNF- $\alpha$-stimulated macrophage inflammatory peptide- 2 and IL- $1 \beta$ release but also concomitantly stimulate IL-4 (36) in in vivo models. It is thus likely that lipoxin bioactions in vivo are up-regulated by cytokines and that lipoxins directly modulate the cytokine composition in a local inflammatory milieu, a concept supported by recent findings showing that $\mathrm{LXA}_{4}$ may be involved in a negative feedback loop opposing inflammatory cytokine-induced activation of human synovial fibroblasts (28).

Unlike PMN and eosinophils, lipoxins are potent stimuli for peripheral blood monocytes (3). While $\mathrm{LXA}_{4}$ and $\mathrm{LXB}_{4}$ stimulate monocyte chemotaxis and adherence, these cells do not degranulate or release reactive oxygen species in response to lipoxins, suggesting that the actions of these lipoxins are specific for locomotion and may be related to the recruitment of monocytes to sites of injury. These monocyte activities may be host-protective in view of the important role of these cells in wound healing and resolution of inflammatory sites. Along with these suggestions, $\mathrm{LXA}_{4}$ and $\mathrm{LXA}_{4}$ analogs were shown to accelerate the resolution of allergic pleural edema (37) and enhance phagocytosis of apoptotic PMN by monocyte-derived macrophages (38). It is increasingly appreciated that the resolution of inflammation is a dynamically regulated process and these different observations raise the possibility that lipoxins play pivotal roles in the resolution phase of PMN-mediated inflammation.

\section{Lipoxins in disease models}

Lipoxin formation is observed when cells are exposed to receptor-mediated soluble or phagocytic stimuli. Because cells routinely encounter these stimuli and lipoxins perform vasoactive and counterregulatory actions, $\mathrm{LXA}_{4}$ and $\mathrm{LXB}_{4}$ are likely to have

Table 2. Lipoxins (LX) and diseases.

\begin{tabular}{|c|c|c|}
\hline Organ/system & Impact in vivo & Reference \\
\hline \multirow[t]{3}{*}{ Hematologic and oncologic } & $\begin{array}{l}\text { - Defect in LX production with cells from chronic myeloid } \\
\text { leukemia patients in blast crisis }\end{array}$ & 39 \\
\hline & - LX stimulate nuclear form of PKC in erythroleukemia cells & 40 \\
\hline & - Formation of LX by granulocytes from eosinophilic donors & 41 \\
\hline Vascular & - Angioplasty-induced plaque rupture triggers LX formation & 42 \\
\hline \multirow[t]{2}{*}{ Renal } & $\begin{array}{l}\text { - LX trigger renal hemodynamic changes generated in } \\
\text { experimental glomerular nephritis }\end{array}$ & 43 \\
\hline & - Increased LX excretion in rat kidney transfected with rh15-LO & 44 \\
\hline \multirow[t]{2}{*}{ Dermatologic } & - $\mathrm{LXA}_{4}$ regulates delayed hypersensitive reactions in skin & 45 \\
\hline & - LX inhibit PMN infiltration and vascular permeability & 46 \\
\hline \multirow[t]{4}{*}{ Pulmonary } & $\begin{array}{l}\text { - } \mathrm{LXA}_{4} \text { detected in bronchoalveolar lavage fluids from patients } \\
\text { with pulmonary disease and asthma }\end{array}$ & 47 \\
\hline & - Production of $L X$ by nasal polyps and bronchial tissue & 48 \\
\hline & $\begin{array}{l}\text { - } \mathrm{LXA}_{4} \text { inhalation shifts and reduces } \mathrm{LTC}_{4} \text {-induced contraction } \\
\text { in asthmatic patients }\end{array}$ & 32 \\
\hline & $\begin{array}{l}\text { - Aspirin-intolerant asthmatics display a lower biosynthetic } \\
\text { capacity than aspirin-tolerant patients }\end{array}$ & 49 \\
\hline Hepatic & - LX generation decreased in cirrhotic patients & 50 \\
\hline Rheumatoid arthritis & - LX levels increase with recovery & 51 \\
\hline
\end{tabular}


physiologic roles during homeostatic responses even in the absence of illness. Lipoxins are generated in vivo in humans and in experimental animal models (reviewed in 34) and are also associated with diseases (Table 2). Currently, only limited data on the effects of lipoxins in clinical investigation are available. Nevertheless, in asthmatic patients, inhalation of $\mathrm{LXA}_{4}$ inhibits $\mathrm{LTC}_{4}$ induced airway obstruction (32). Lipoxins are generated from endogenous sources during provocative challenge in asthma (6), suggesting that they may play roles in modulating airway hyperresponsiveness. Asthmatic patients possess the capacity to generate both lipoxins and 15-epi-lipoxins, but aspirin-intolerant asthmatics display a lower biosynthetic capacity than aspirin-tolerant asthmatics for these potentially protective lipid mediators (49). In addition, lipoxins are formed in human airways in vivo during certain inflammatory lung diseases (e.g., sarcoidosis, alveolitis and resolving pneumonia) (52), in cirrhotic ascites (50) and intravascularly after percutaneous transluminal angioplasty of atherosclerotic coronary diseases (42). Together, these data support a physiological role for lipoxins in vivo.

\section{Anti-inflammatory signaling and lipoxin-specific receptors}

Lipoxin actions are cell type, species and organ specific. These actions can be assigned to one or a combination of three mechanisms: a) lipoxins act at their own specific cell surface receptors (i.e., $\mathrm{LXA}_{4}$ specific and separate $\mathrm{LXB}_{4}$ receptor) $(53,54)$; b) $\mathrm{LXA}_{4}$ interacts with a subclass of the peptido-leukotriene $\left(\mathrm{LTC}_{4}\right.$ and $\left.\mathrm{LTD}_{4}\right)$ receptor that also binds $\mathrm{LXA}_{4}(14)$, and c) lipoxins can act on intracellular targets after lipoxin transport and uptake or within their cells of origin (55).

$\mathrm{LXA}_{4}$ and $\mathrm{LXB}_{4}$ act at two distinct sites, and in some cell types, they evoke similar actions, but their actions are distinct in others. ${ }^{3} \mathrm{H}-\mathrm{LXA}_{4}$ specifically binds to intact
PMN, the binding being modulated by stable guanosine analogs (53), suggesting that $\mathrm{LXA}_{4}$-triggered responses in PMN are mediated by classical G-protein coupling of cell surface receptors. The bioactions of $\mathrm{LXA}_{4}$, 15-epi-LXA ${ }_{4}$ and stable analogs are transduced by this high affinity receptor (lipoxin $\mathrm{A}_{4}$ receptor, ALXR) that has been sequenced and cloned for both mouse (46) and human leukocytes $(19,22)$, as well as human enterocytes (26) and, more recently, for mesangial cells (31). In addition, $\mathrm{LXA}_{4}$ actions on vascular endothelial cells are mediated via a distinct non-myeloid receptor that remains to be cloned.

Mouse ALXR isolated from a spleen cDNA library had a characteristic sequence of seven transmembrane spanning G protein-coupled receptors and its homology to the human ALXR (56) was $73 \%$ at the deduced amino acid level. Mouse ALXR showed high affinity binding to ${ }^{3} \mathrm{H}-\mathrm{LXA}_{4}$ $\left(K_{\mathrm{d}} 1.5 \mathrm{nM}\right)$, with values similar to those obtained with the human receptor $(1.7 \mathrm{nM})$ expressed in $\mathrm{CHO}$ cells (46). $\mathrm{CHO}$ cells stably transfected with mouse ALXR and exposed to $\mathrm{LXA}_{4}$ selectively hydrolyzed guanine triphosphate $(46,56)$, indicating that $\mathrm{LXA}_{4}$ stimulates functional coupling of ALXR and G protein. Tissue distribution of mouse ALXR mRNA paralleled the appearance of human ALXR mRNA, and this mRNA was most abundant in mouse neutrophils, followed by spleen and lung.

In several tissues and cell types other than leukocytes, results of pharmacological experiments have indicated that $\mathrm{LXA}_{4}$ can also interact with a subclass of peptido-leukotriene receptors (cysLT ${ }_{1}$ ) as a partial agonist mediating their actions (31). Along these lines, both $\mathrm{LTC}_{4}$ and $\mathrm{LXA}_{4}$, albeit at high concentrations $(>1 \mu \mathrm{M})$, induce contractions of guinea pig lung parenchyma and release of thromboxane $A_{2}$ which is sensitive to cysLT $_{1}$-receptor antagonists (57), an event which is not likely to be a physiologic action of $\mathrm{LXA}_{4}$. 
In addition to specific binding to membrane surface receptors, specific binding of labeled $\mathrm{LXA}_{4}$ is associated with subcellular fractions including granules and nucleus (53). In this regard, it was recently reported that $\mathrm{LXA}_{4}$ binds to and activates the aryl hydrocarbon receptor, a ligand-activated transcription factor, in a murine hepatoma cell line (58).

Our current understanding of the $\mathrm{LXA}_{4}$ receptor's intracellular down-regulatory signals remains incomplete. In neutrophils, for example, lipoxins do not promote a sustained mobilization of intracellular $\mathrm{Ca}^{2+}$, acidification of the intracellular milieu or generation of cAMP. But, $\mathrm{LXA}_{4}$ binding to its receptor triggers the activation of GTPase, phospholipase $\mathrm{A}_{2}$ and phospholipase $\mathrm{D}$ (reviewed in 7), responses that are inhibited by pretreatment of the cells with pertussis toxin. In addition, lipoxins are not receptor level antagonists for inflammatory stimuli such as fMLP or $\mathrm{LTB}_{4}$. For example, lipoxins inhibit $\mathrm{LTB}_{4}$ responses in neutrophils perhaps by uncoupling $\mathrm{LTB}_{4}$ receptor-initiated proinflammatory signaling, as evidenced by downregulation of $\mathrm{CD} 11 \mathrm{~b} / \mathrm{CD} 18$, decreased $\mathrm{IP}_{3}$ formation and changes in intracellular protein kinase $\mathrm{C}$ distribution (7). Recently, a novel polyisoprenyl phosphate signaling pathway was identified (59) with one of its components, presqualene diphosphate(PSDP), being a potent negative intracellular signal in PMN. Activation of ALXR inhibits PSDP remodeling, leading to an accumulation of PSDP and potent inhibition of both phospholipase D and superoxide anion generation (18) in PMN.

The receptor coupling in monocytes and PMN is similar to G-protein activation, being critical in both cell types. However, there could be different G-protein subtypes that diverge downstream in the signal transduction pathway to stimulate monocytes and inhibit PMN (Figure 5).

It was recently shown (54) that small peptides selectively compete for specific ${ }^{3} \mathrm{H}-$
$\mathrm{LXA}_{4}$ binding with PMN and recombinant human ALXR, increasing extracellular acidification rates and inducing cell chemotaxis and migration in vivo. Chimeric receptors constructed from receptors with opposing functions, namely ALXR and $\mathrm{LTB}_{4}$ (54), revealed that the seventh transmembrane segment and adjacent regions of ALXR are essential for $\mathrm{LXA}_{4}$ recognition, and additional regions of this receptor are required for high affinity binding of the peptide ligands. It appears, however, that the Gprotein interactions evoked by ligand-receptor binding and their intracellular amplification mechanisms are different for peptide versus lipid ligands of ALXR, and hence they can dictate different functional responses.

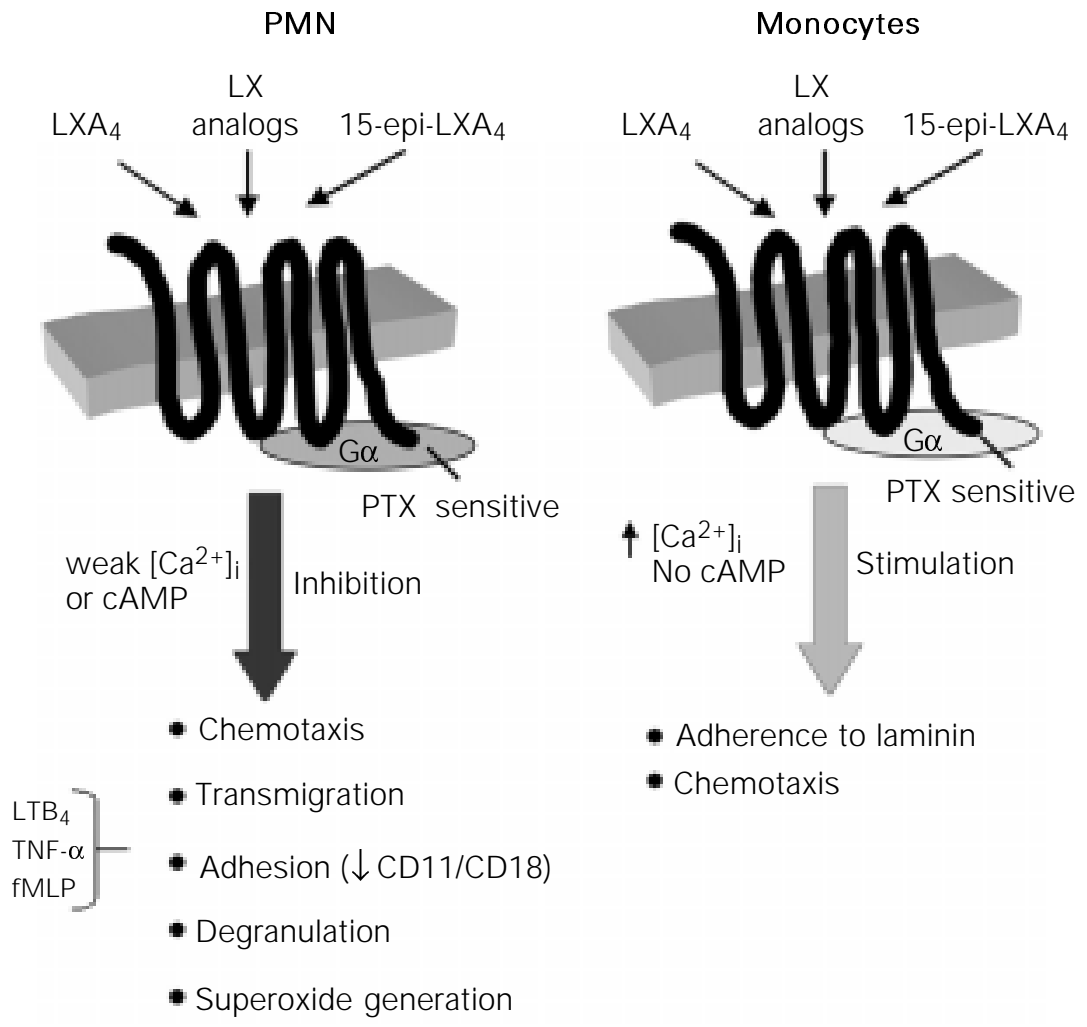

Figure 5. Activation of the lipoxin ( $L X) A_{4}$ receptor (ALXR) evokes different responses in neutrophils (PMN) and monocytes. The activation of the ALXR inhibits PMN and stimulates monocyte function via pertussis toxin (PTX)-sensitive $G$ proteins $(G \alpha)$ upon activation by $\mathrm{LXA}_{4}, 15-e p i-\mathrm{LXA}_{4}$ and lipoxin analogs. $\mathrm{LTB}_{4}$, leukotriene $\mathrm{B}_{4} ; \mathrm{TNF}-\alpha$, tumor necrosis factor $\alpha ; f M L P$, formyl-methionyl-leucyl-phenylalanine. 


\section{Conclusions}

Lipoxins are the trihydroxytetraene-containing class of eicosanoids primarily generated by cell-cell interactions via transcellular biosynthesis, serving as local endogenous anti-inflammatory mediators. These stop signals in inflammation and other related processes may be involved in switching the cellular response from additional PMN recruitment to monocytes that could lead to resolution of the inflammatory response or promotion of repair and wound healing. Aspirin impinges on this system and evokes the endogenous biosynthesis of the 15 epimers of lipoxins, namely ATL, that can modulate in part the beneficial actions of aspirin.

Lipoxins and ATL analogs represent useful tools to evaluate the potential of pharmacological manipulation of the inflammatory process as a means to develop new and selective anti-inflammatory therapies with reduced unwanted toxic side effects. In this context, it was recently described (60) that aspirin and other nonsteroidal anti-inflammatory drugs together with dietary omega-3 polyunsaturated fatty acid supplementation induce the generation of a novel array of bioactive compounds such as 5,12,18R-tri HEPE. Together with lipoxins and 15-epilipoxins, the identification of these novel endogenous anti-inflammatory lipid mediators opens new avenues in the therapeutics of inflammation, cardiovascular diseases and cancer.

\section{Acknowledgments}

The authors thank Mary H. Small for assistance with the preparation of the manuscript.

\section{References}

1. Cotran RS, Kumar V \& Collins T (1999). Robbins Pathologic Basis of Disease. 6th edn. W.B. Saunders Co., Philadelphia.

2. Qiu FH, Wada K, Stahl GL \& Serhan CN (2000). IMP and AMP deaminase in reperfusion injury down-regulates neutrophil recruitment. Proceedings of the National Academy of Sciences, USA, 97: 42674272.

3. Serhan CN (1999). Lipoxins and aspirintriggered 15-epi-lipoxins. In: Gallin JI \& Snyderman R (Editors), Inflammation. Basic Principles and Clinical Correlates. Lippincott Williams \& Wilkins, Philadelphia.

4. Claria J \& Serhan CN (1995). Aspirin triggers previously undescribed bioactive eicosanoids by human endothelial cell-leukocyte interactions. Proceedings of the National Academy of Sciences, USA, 92: 9475-9479.

5. Serhan CN, Haeggestrom J Z \& Leslie CC (1996). Lipid mediator networks in cell signaling: update and impact of cytokines. FASEB J ournal, 10: 1147-1158.

6. Levy BD, Bertram S, Tai HH, Israel E, Fischer A, Drazen J M \& Serhan CN (1993). Agonist-induced lipoxin A4 generation: detection by a novel lipoxin A4-ELISA. Lipids, 28: 1047-1053.

7. Serhan CN (1994). Lipoxin biosynthesis and its impact in inflammatory and vascular events. Biochimica et Biophysica Acta, 1212: 1-25.

8. Pettitt TR, Rowley AF, Barrow SE, Mallet Al \& Secombes CJ (1991). Synthesis of lipoxins and other lipoxygenase products by macrophages from the rainbow trout, Oncorhynchus mykiss. J ournal of Biological Chemistry, 266: 8720-8726.

9. Chiang N, Takano T, Clish CB, Petasis NA, Tai HH \& Serhan CN (1998). Aspirin-triggered 15-epi-LXA 4 generation by costimulation of human peripheral blood cell types and in a mouse acute peritonitis model: Development of a specific 15-epi$\mathrm{LXA}_{4}$ ELISA. J ournal of Pharmacology and Experimental Therapeutics, 287: 779-790.

10. Serhan CN, Maddox JF, Petasis NA, Akritopoulou-Zanze I, Papayianni A, Brady HR, Colgan SP \& Madara J L (1995). Design of lipoxin $\mathrm{A}_{4}$ stable analogs that block transmigration and adhesion of human neutrophils. Biochemistry, 34: 1460914615.

11. Clish CB, Levy BD, Chiang N, Tai HH \&
Serhan CN (2000). Oxidoreductases in lipoxin $\mathrm{A}_{4}$ metabolic inactivation. A novel role for 15-oxoprostaglandin 13-reductase/leukotriene $\mathrm{B}_{4}$ 12-hydroxydehydrogenase in inflammation. Journal of Biological Chemistry, 275: 25372-25380.

12. Maddox J F, Colgan SP, Clish CB, Petasis NA, Fokin W \& Serhan CN (1998). Lipoxin $\mathrm{B}_{4}$ regulates human monocyte/neutrophil adherence and motility: design of stable lipoxin $\mathrm{B}_{4}$ analogs with increased biologic activity. FASEB J ournal, 12: 487-494.

13. Clish CB, O'Brien J A, Gronert K, Stahl GL, Petasis NA \& Serhan CN (1999). Local and systemic delivery of a stable aspirin-triggered lipoxin prevents neutrophil recruitment in vivo. Proceedings of the National Academy of Sciences, USA, 96: 82478252.

14. Dahlen S-E \& Serhan CN (1991). Lipoxins: bioactive lipoxygenase interaction products. In: Wong A \& Crooke ST (Editors), Lipoxygenases and their Products. Academic Press, San Diego.

15. Lee TH, Horton CE, Kyan-Aung U, Haskard D, Crea AE \& Spur BW (1989). Lipoxin $A_{4}$ and lipoxin $\mathrm{B}_{4}$ inhibit chemotactic responses of human neutrophils stimulated 
by leukotriene $\mathrm{B}_{4}$ and $\mathrm{N}$-formyl-L-methionyl-L-leucyl-L-phenylalanine. Clinical Science, 77: 195-203.

16. Colgan SP, Serhan CN, Parkos CA, DelpArcher C \& Madara J L (1993). Lipoxin A4 modulates transmigration of human neutrophils across intestinal epithelial monolayers. J oumal of Clinical Investigation, 92: 75-82.

17. Papayianni $A$, Serhan $C N \&$ Brady $H R$ (1996). Lipoxin $A_{4}$ and $B_{4}$ inhibit leukotriene-stimulated interactions of human neutrophils and endothelial cells. J ournal of Immunology, 156: 2264-2272.

18. Levy BD, Fokin W, Clark J M, Wakelam MJ O, Petasis NA \& Serhan CN (1999). Polyisoprenyl phosphate (PIPP) signaling regulates phospholipase $D$ activity: a "stop" signaling switch for aspirin-triggered lipoxin $A_{4}$. FASEB J ournal, 13: 903911.

19. Fiore $S \&$ Serhan CN (1995). Lipoxin $A_{4}$ receptor activation is distinct from that of the formyl peptide receptor in myeloid cells: inhibition of $C D 11 / 18$ expression by lipoxin $A_{4}$-lipoxin $A_{4}$ receptor interaction. Biochemistry, 34: 16678-16686.

20. Grandordy BM, Lacroix H, Mavoungou K, Krilis S, Crea AEG, Spur BW \& Lee TH (1990). Lipoxin A4 inhibits phosphoinositide hydrolysis in human neutrophils. Biochemical and Biophysical Research Communications, 167: 1022-1029.

21. FilepJ G, Zouki C, Petasis NA, Hachicha M \& Serhan CN (1999). Anti-inflammatory actions of lipoxin $\mathrm{A}_{4}$ stable analogs are demonstrable in human whole blood: modulation of leukocyte adhesion molecules and inhibition of neutrophil-endothelial interactions. Blood, 94: 4132-4142.

22. Maddox J F, Hachicha M, Takano T, Petasis NA, Fokin W \& Serhan CN (1997). Lipoxin $\mathrm{A}_{4}$ stable analogs are potent mimetics that stimulate human monocytes and THP-1 cells via a G-protein linked lipoxin $\mathrm{A}_{4}$ receptor. J ournal of Biological Chemistry, 272: 6972-6978.

23. Bandeira-Melo C, Bozza PT, Diaz BL, Cordeiro RSB, J ose PJ, Martins MA \& Serhan CN (2000). Cutting edge: Lipoxin (LX) $\mathrm{A}_{4}$ and aspirin-triggered 15-epi-LXA 4 block allergen-induced eosinophil trafficking. J ournal of Immunology, 164: 22672271.

24. Ramstedt U, Serhan CN, Nicolaou KC, Webber SE, Wigzell H \& Samuelsson B (1987). Lipoxin A-induced inhibition of human natural killer cell cytotoxicity: studies on stereospecificity of inhibition and mode of action. J ournal of Immunology, 138: $266-270$.
25. Stenke L, Reizenstein P \& Lindgren J A (1994). Leukotrienes and lipoxins - new potential performers in the regulation of human myelopoiesis. Leukemia Research, 18: 727-732.

26. Gronert K, Gewirtz A, Madara L \& Serhan CN (1998). Identification of a human enterocyte lipoxin $A_{4}$ receptor that is regulated by interleukin (IL)-13 and interferon $\gamma$ and inhibits tumor necrosis factor $\alpha$ induced IL-8 release. J ournal of Experimental Medicine, 187: 1285-1294.

27. Gewirtz AT, McCormick B, Neish AS, Petasis NA, Gronert K, Serhan CN \& Madara J L (1998). Pathogen-induced chemokine secretion from model intestinal epithelium is inhibited by lipoxin A4 analogs. J ournal of Clinical Investigation, 101: 1860-1869.

28. Sodin-Semrl S, Taddeo B, Tseng D, Varga $J$ \& Fiore $S$ (2000). Lipoxin $A_{4}$ inhibits IL$1 ß$-induced IL-6, IL-8, and matrix metalloproteinase-3 production in human synovial fibroblasts and enhances synthesis of tissue inhibitors of metalloproteinases. J ournal of Immunology, 164: 2660-2666.

29. Leszczynski D \& Ustinov J (1990). Protein kinase C-regulated production of prostacyclin by rat endothelium is increased in the presence of lipoxin A4. FEBS Letters, 263: 117-120.

30. Scalia R, Gefen J, Petasis NA, Serhan CN \& Lefer AM (1997). Lipoxin A4 stable analogs inhibit leukocyte rolling and adherence in the rat mesenteric microvasculature: role of P-selectin. Proceedings of the National Academy of Sciences, USA, 94: 9967-9972.

31. McMahon B, Stenson C, McPhillips F, Fanning A, Brady HR \& Godson C (2000). Lipoxin $A_{4}$ antagonizes the mitogenic effects of leukotriene $D_{4}$ in human renal mesangial cells. Differential activation of MAP kinases through distinct receptors. J ournal of Biological Chemistry, 275: 27566-27575.

32. Christie PE, Spur BW \& Lee TH (1992). The effects of lipoxin $A_{4}$ on airway responses of asthmatic subjects. American Review of Respiratory Diseases, 145: 1281-1284.

33. Tamaoki J , Tagaya E, Yamawaki I \& Konno K (1995). Lipoxin $A_{4}$ inhibits cholinergic neurotransmission through nitric oxide generation in the rabbit trachea. European J ournal of Pharmacology, 287: 233-238.

34. Serhan CN (1997). Lipoxins and novel aspirin-triggered 15-epi-lipoxins (ATL): a jungle of cell-cell interactions or a therapeutic opportunity? Prostaglandins, 53: 107137.
35. Chiang N, Gronert K, Clish CB, O'Brien J A, Freeman MW \& Serhan CN (1999). Leukotriene $\mathrm{B}_{4}$ receptor transgenic mice reveal novel protective roles for lipoxins and aspirin-triggered lipoxins in reperfusion. J ournal of Clinical Investigation, 104: 309-316.

36. Hachicha $M$, Pouliot $M$, Petasis NA \& Serhan CN (1999). Lipoxin (LX)A 4 and aspirin-triggered 15-epi-LXA 4 inhibit tumor necrosis factor $\alpha$-induced neutrophil responses and trafficking: regulators of a cytokine-chemokine axis. J ournal of Experimental Medicine, 189: 1923-1929.

37. Bandeira-Melo $C$, Serra MF, Dias $B L$, Cordeiro RSB, Silva PMR, Lenzi HL, Bakhle YS, Serhan CN \& Martins MA (2000). Cyclooxygenase-2-derived prostaglandin $\mathrm{E}_{2}$ and lipoxin $\mathrm{A}_{4}$ accelerate resolution of allergic edema in Angiostrongylus costaricensis-infected rats: relationship with concurrent eosinophilia. J ournal of Immunology, 164: 1029-1036.

38. Godson C, Mitchell S, Harvey KH, Petasis NA, Hogg N \& Brady HR (2000). Cutting edge: Lipoxins rapidly stimulate nonphlogistic phagocytosis of apoptotic neutrophils by monocyte-derived macrophages. J ournal of Immunology, 164: 1663-1667.

39. Stenke L, Edenius C, Samuelsson J \& Lindgren J A (1991). Deficient lipoxin synthesis: a novel platelet dysfunction in myeloproliferative disorders with special reference to blast crisis of chronic myelogenous leukemia. Blood, 78: 2989-2995.

40. Beckman BS, Despinasse BP \& Spriggs L (1992). Actions of lipoxins $A_{4}$ and $B_{4}$ on signal transduction events in Friend erythroleukemia cells. Proceedings of the Society for Experimental Biology and Medicine, 201: 169-173.

41. Serhan CN, Hirsch U, Palmblad J \& Samuelsson B (1987). Formation of lipoxin A by granulocytes from eosinophilic donors. FEBS Letters, 217: 242-246.

42. Brezinski DA, Nesto RW \& Serhan CN (1992). Angioplasty triggers intracoronary leukotrienes and lipoxin $\mathrm{A}_{4}$. Impact of aspirin therapy. Circulation, 86: 56-63.

43. Katoh T, Takahashi K, DeBoer DK, Serhan CN \& Badr KF (1992). Renal hemodynamic actions of lipoxins in rats: a comparative physiological study. American J ournal of Physiology, 263: F436-F442.

44. Munger KA, Montero A, Fukunaga M, Uda S, Yura T, Imai E, Kaneda $Y$, Valdivielso J M \& Badr KF (1999). Transfection of rat kidney with human 15-lipoxygenase suppresses inflammation and preserves function in experimental glomerulonephritis. Proceedings of the National Academy of 
Sciences, USA, 96: 13375-13380.

45. Feng Z, Godfrey HP, Mandy S, Strudwick S, Lin K-T \& Heilman E (1996). Leukotriene $B_{4}$ modulates in vivo expression of delayed-type hypersensitivity by a receptor-mediated mechanism: regulation by lipoxin $A_{4}$. J ournal of Pharmacology and Experimental Therapeutics, 278: 950-956.

46. Takano T, Fiore S, Maddox J F, Brady HR, Petasis NA \& Serhan CN (1997). Aspirintriggered 15-epi-lipoxin $\mathrm{A}_{4}\left(\mathrm{LXA}_{4}\right)$ and $\mathrm{LXA}_{4}$ stable analogs are potent inhibitors of acute inflammation: evidence for antiinflammatory receptors. J oumal of Experimental Medicine, 185: 1693-1704.

47. Chavis $C$, Chanez $P$, Vachier I, Bousquet J, Michel FB \& Godard P (1995). 5-15diHETE and lipoxins generated by neutrophils from endogenous arachidonic acid as asthma biomarkers. Biochemical and Biophysical Research Communications, 207: 273-279.

48. Edenius $C$, Kumlin M, Bjork T, Anggard A \& Lindgren J A (1990). Lipoxin formation in human polyps and bronchial tissue. FEBS Letters, 272: 25-28.

49. Sanak M, Levy BD, Clish CB, Chiang N, Gronert K, Mastalerz L, Serhan CN \& Szczeklik A (2000). Aspirin-tolerant asthmatics generate more lipoxins than aspirin-intolerant asthmatics. European Respiratory J ournal, 16: 1-6.
50. Claria J , Titos E, J imenez W, Ros J , Gines P, Arroyo V, Rivera F \& Rodes J (1998). Altered biosynthesis of leukotrienes and lipoxins and host defense disorders in patients with cirrhosis and ascites. Gastroenterology, 115: 147-156.

51. Thomas E, Leroux J L, Blotman F \& Chavis C (1995). Conversion of endogenous arachidonic acid to 5,15-diHETE and lipoxins by polymorphonuclear cells from patients with rheumatoid arthritis. Inflammation Research, 44: 121-124.

52. Lee TH, Crea AEG, Gant V, Spur BW, Marron BE, Nicolaou KC, Reardon E, Brezinski M \& Serhan CN (1990). Identification of lipoxin $\mathrm{A}_{4}$ and its relationship to the sulfidopeptide leukotrienes $\mathrm{C}_{4}, \mathrm{D}_{4}$, and $\mathrm{E}_{4}$ in the bronchoalveolar lavage fluids obtained from patients with selected pulmonary diseases. American Review of Respiratory Disease, 141: 1453-1458.

53. Fiore S, Ryeom SW, Weller PF \& Serhan CN (1992). Lipoxin recognition sites. Specific binding of labeled lipoxin $A_{4}$ with human neutrophils. J ournal of Biological Chemistry, 267: 16168-16176.

54. Chiang N, Fierro IM, Gronert K \& Serhan CN (2000). Activation of lipoxin $\mathrm{A}_{4}$ receptors by aspirin-triggered lipoxins and selected peptides evokes ligand-specific responses in inflammation. J ournal of Experimental Medicine, 191: 1197-1207.
55. Simchowitz L, Fiore $\mathrm{S} \&$ Serhan $\mathrm{CN}$ (1994). Carrier-mediated transport of lipoxin A4 in human neutrophils. American J ournal of Physiology, 267: C1525-C1534.

56. Fiore S, Maddox J F, Perez HD \& Serhan CN (1994). Identification of a human cDNA encoding a functional high affinity lipoxin $\mathrm{A}_{4}$ receptor. J ournal of Experimental Medicine, 180: 253-260.

57. Wikstrosm J onsson $E$, Rosenqvist $U \&$ Dahlen SE (1998). Agonist and antagonist activities of the leukotriene analogue BAY u9773 in guinea pig lung parenchyma. European J ournal of Pharmacology, 357: 203-211.

58. Schaldach CM, Riby J \& Bjeldanes LF (1999). Lipoxin $A_{4}$ : a new class of ligand for the Ah receptor. Biochemistry, 38: 7594-7600.

59. Levy BD, Petasis NA \& Serhan CN (1997). Polyisoprenyl phosphates in intracellular signaling. Nature, 389: 985-989.

60. Serhan CN, Clish CB, Brannon J, Colgan SP, Chiang N \& Gronert K (2000). Novel functional sets of lipid-derived mediators with anti-inflammatory actions generated from omega-3 fatty acids via cyclooxygenase-2-NSAIDs and transcellular processing. J ournal of Experimental Medicine, 192: 1197-1204. 